\title{
Alegorías subversivas de la memoria: una lectura comparativa de En estado de memoria de Tununa Mercado y Los topos de Félix Bruzzone
}

Desde modalidades enunciativas contrastantes, vinculadas a sus respectivos contextos de producción, En estado de memoria (1990) de Tununa Mercado $y$ Los topos (2008) de Félix Bruzzone funcionan a contracorriente del canon narrativo de la memoria de postdictadura argentina. Ambos relatos abandonan toda pretensión de verdad histórica a favor de construcciones subjetivas inestables, sin renunciar a la dimensión ética del trabajo colectivo de rememoración, sino inscribiéndola precisamente en el acto de denunciar discursos, hábitos o dispositivos encaminados a hacer del sujeto de memoria un vehículo de dicha pretensión de verdad. Si se tiene en cuenta la doble función restitutiva y prospectiva de la alegoría, central en ambos relatos, se hace evidente la tematización del riesgo de convertir el deber ético de la memoria en imperativo esencialista. La lectura alegórica resuelve igualmente la aparente paradoja (restitución por textualización vs destitución por somatización) que surge al leer ambos textos como síntomas de la aceptación o negación del imperativo de duelo. En última instancia, ambos relatos suponen una disociación momentánea entre la escritura como praxis subversiva y la literatura como institución de memoria cultural, mecanismo metaficticio que, siguiendo a Guy Debord, denomino détournement mnemónico.

"Pero cuando los recuerdos históricos se hacen demasiado abrumadores, el hombre deja de nuevo de ser, y si no poseyese ese ambiente no-histórico jamás comenzaría a ser, jamás se atrevería a comenzar". Federico Nietzsche, De la utilidad y los inconvenientes de los estudios históricos para la vida 
“[N]o hay mejor punto de arranque para el pensamiento que la risa. Y una conmoción del diafragma ofrece casi siempre mejores perspectivas al pensamiento que la conmoción del alma".

Walter Benjamin, Tentativas sobre Brecht

El epígrafe de Nietzsche con que comienzo este ensayo resume la problemática central que, en mi lectura, atraviesa la novela Los topos (2008) de Félix Bruzzone y permite compararla al relato de Tununa Mercado, En estado de memoria (1990), con el objetivo de poner en evidencia ciertas variaciones intergeneracionales en la elaboración textual de la memoria de postdictadura argentina. Se trata del imperativo de la memoria que, oculto bajo formas sutiles o institucionalizadas, incapacita al sujeto para la acción. En su "tipología sobre los usos y abusos de la memoria natural", Paul Ricoeur señala que "ce texte [de Nietzsche] unit dans une sémiologie complexe le traitement médical des symptômes et le traitement philologique de tropes ... Le ton est donné pour un traitement similaire ... précisément de la mémoire collective ... C'est ... en tant qu'exercée que la mémoire tombe sous ce point de vue" (Mémoire 83). Hay aquí dos campos discursivos que los relatos ponen en tensión: el científico o psicológico, que aborda los cuerpos considerados enfermos, y el retórico o literario, que remite a la mediación del lenguaje en toda configuración textual. Existe también una premisa: la memoria colectiva es una dinámica intersubjetiva (no una representación mimética de algo más) en cuyo ejercicio radica la posibilidad de un uso abusivo del pasado en el presente. $\mathrm{Y}$ es precisamente la consciencia de ese abuso - su amenaza percibida de manera retrospectiva desde la posición de quien conoce las consecuencias de un dominio que opera por encima de otro, específico del presente del relato o la escritura (la dictadura militar, el exilio, o el espectáculo neoliberal) - lo que, según defiendo, establece un núcleo temático entre los dos textos que aquí comparo.

Al considerar la cuestión formal en los relatos de memoria colectiva desde una perspectiva centrada en el sujeto de enunciación, Leonor Arfuch recuerda que en ellos se articula "trabajosamente, afecto, imaginación y reflexión. Aquí, las modalidades del decir marcan fuertemente la dimensión ética de lo dicho: la posición del enunciador, su papel en la trama, su (auto)valoración, la posibilidad de elaboración y de distancia crítica" (8o). Si, siguiendo a Ricoeur, aceptamos que "toda problemática de la identidad personal va a girar en torno a [la] búsqueda de una invariante relacional, dándole el significado fuerte de permanencia en el tiempo" (Sí 
mismo 112), y coincidimos con Idelber Avelar en que "el imperativo del duelo es el imperativo postdictatorial por excelencia" (286), estaremos admitiendo que, en contexto de postdictadura, la problemática de la identidad personal que se impone es la de realizar el duelo. Desde esa perspectiva, los relatos que aquí abordamos narrarían dos búsquedas de esa "invariante relacional" que permite "establecer una relación salvífica con un objeto irrevocablemente perdido" (Avelar 287), resemantizando al sujeto que lleva a cabo el duelo, quien, a su vez, le da un nuevo significado al material del pasado en una doble apertura hacia el futuro: la identitaria y la textual. Dicha interpretación estaría centrada en la identidad narrativa que, siguiendo a Ricoeur, es "una estructura de la experiencia capaz de integrar las dos grandes clases de relatos", el de la historia y el de la ficción, cuyo "entrecruzamiento desvía la atención de las dificultades ligadas al problema de la identidad como tal" (Sí mismo 107).

Una primera aproximación comparativa a nivel de la trama reforzaría la lectura casi consensual de la crítica, al señalar ambos relatos como elaboraciones de una doble crisis, de identidad y de representación, secuelas del pasado autoritario, que a su vez provocara la crisis de confianza ante las instituciones culturales, sociales y políticas de ese momento. Desde esta perspectiva, la experiencia postdictatorial actuada en estos discursos estaría sugiriendo un contraste radical entre la textualización de la memoria como compromiso con el pasado desde el presente - en el texto de Mercado - y la somatización de la memoria como fuga de lo pretérito hacia lo actual - en la novela de Bruzzone. Esta oposición plantea una paradoja si se considera la antítesis entre el tono con que cada narrador emprende el supuesto duelo - grave en Mercado, paródico en Bruzzone - y el saldo que sus respectivas posturas éticas deja en el sujeto de memoria: construcción subjetiva y restitución de lo social en Mercado; disolución subjetiva y destitución de lo social en Bruzzone. Pese al optimismo de la apuesta inicial por el olvido positivo, las nuevas generaciones confiarían más en la imaginación que en la reflexión, en la supervivencia afectiva y libidinal que en el intercambio solidario, y en la expresividad práctica del cuerpo que en la capacidad configurativa del lenguaje como instancias de autofiguración e intercambio subjetivo.

Mi lectura busca romper la fatalidad que resulta al vincular la identidad narrativa y el imperativo del duelo postdictatorial en un afán de cartografiar la superación del pasado traumático. Plantea también la lectura de estos relatos menos como síntomas de sus contextos y del carácter emblemático del sujeto que los formula, y más como textos en los que se considera sus rasgos formales y la intencionalidad explícita que emiten contra los prejuicios de lectura desde los cuales se saben leídos. Al 
no ser representaciones miméticas, la tematización de la memoria (no en tanto facultad individual, sino en tanto ejercicio colectivo) se inscribe en ambas novelas de manera autoconsciente, lo que obliga a considerar ante todo su dimensión metaficticia y abordarlas como discursos metamemorísticos. Puesto que el duelo no termina al final de los textos, y que forma y contenido son un todo igualmente problemático $\mathrm{e}$ inconclusivo, son las modalidades discursivas las que, al margen de los límites genéricos y la distancia al referente cultural, revelan posturas éticas, resistencias y móviles afectivos que pueden ser opuestos a la mera trayectoria de búsqueda - entendida como duelo - que se escenifica en ambos. Si en la oposición freudiana duelo-melancolía, la repetición es el síntoma más reconocible de la incapacidad de superar un trauma, siendo la melancolía y la somatización dos formas de asimilar la identidad al pasado y evitar un reposicionamiento hacia el futuro, parece útil recurrir al concepto de détournement de Guy Debord para designar al mecanismo que, desde el relato literario de memoria, subvierte las tendencias totalizadoras de otros dispositivos, discursos o instituciones de memoria. ${ }^{1}$

$\mathrm{Si}$, como afirma Joël Candau, la memoria colectiva es una forma de metamemoria que resulta "d'un partage hypothétique de souvenirs ... d'une mémoire supposée commune à tous les membres d['un] groupe" (16), estos relatos participan conscientemente de dicha construcción y discuten, con todas sus herramientas retóricas, los presupuestos de la hipotética comunidad de recuerdos. Propongo entender el proceso que media entre un estatuto subjetivo y otro cultural de la puesta en discurso de estos relatos como un doble détournement: uno definitivo (metamemorístico), de los dispositivos que instituyen el imperativo de la memoria; y otro momentáneo (metaficticio) de la literatura en tanto institución mnemónica. Según demuestro, Mercado subvierte el carácter institucional de la literatura para activar su función restitutiva, mientras que Bruzzone la trastoca para afirmar su autoridad discursiva.

EL IMPULSO MELANCÓLICO DE EN ESTADO DE MEMORIA

Escrito al regreso de Tununa Mercado a la Argentina, y compuesto por viñetas que narran en primera persona episodios de los exilios de la autora, En estado de memoria (1990) transgrede el pacto de fidelidad del canon memorialista y autobiográfico. En efecto, no revisita el pasado para indagar elementos verídicos y articular un relato colectivo. ${ }^{2}$ Aunque dialoga críticamente con el contexto traumático de la postdictadura, en esta novela los hechos pasados "no se recuperan sino que se construyen en el presente" (Davidovich 5), y la voz narrativa entabla una búsqueda íntima que "impugna la capacidad representativa del lenguaje" (Jara 158). Estos 
rasgos han llevado a la crítica a considerarlo "el texto fundamental de la postdictadura latinoamericana ... una elaborada red alegórica en la cual se piensa el duelo como condición de la escritura y, a la vez, la escritura como condición de una virtual resolución ... del trabajo postdictatorial del duelo" (Avelar 34):

[E]n el texto de Mercado el proceso de conferirle al otro esa posición de saber - un saber formalizado en el que ella podría tener una existencia como caso - se hace central ... Tratamientos por drogas o terapias de autoayuda, homeopatía, trabajos de grupo o incluso el psicoanálisis no son más que formas diferentes en que esta falta fundamental es objetivada en un sujeto supuesto saber ... [que] transfiere ... de estos casos externos a su propia práctica de la escritura ... Su trayectoria ... concluye con la emergencia de una práctica - la escritura misma - en la que su ignorancia es articulada. El momento análogo al momento psicoanalítico de ruptura de la transferencia ... tiene lugar en el texto cuando la escritura se afirma como el teatro privilegiado del inconsciente. En estado de memoria es un relato en el que el único aprendizaje reside en el abrazo de esa ignorancia. (Avelar 290- 291)

Avelar sostiene que "para Benjamin ... la desolación melancólica ante la miseria pasada no sería, como en Freud, un bloqueo de la praxis, sino todo lo contrario: condición de posibilidad de toda praxis genuina" (283). En estado de memoria estaría escrito bajo el influjo de un "impulso melancólico" (Avelar 283) que, por un lado, justificaría la búsqueda de una autoridad institucional para exteriorizar el duelo; por el otro, posibilitaría el eventual advenimiento de la praxis literaria que se desvanece "como un papel que se desliza vertical en una ranura" (Mercado 197). Esta textualización del duelo permitiría la reinserción social y renovaría el compromiso político. Alberto Moreiras lo establece sin equívocos:

Sólo esa escritura podrá, incluso desde la mayor y más profunda destitución, o precisamente desde ella, restituir la noción misma de comunidad cuya pérdida fue el logro más estable de los años del Proceso ... Esa sorda demanda de restitución desde la destitución es lo que la demanda literaria a la que Mercado responde trata de articular. (397)

Tras afirmar que "[e]scribir el remanente destitucional a partir de la teoría como institución terapéutica conforma el estilo de En estado de memoria" (Moreiras 389) y señalar las múltiples "instituciones del saber" destituidas (Avelar), la crítica no ha abundado en la contradicción implícita en la que Mercado incurre cuando su voz narrativa percibe la literatura como 
institución del saber y, otras veces no. ${ }^{3}$ Parece necesario explorar este bloqueo momentáneo de la institucionalidad de la literatura.

El capítulo inicial relata la identificación de la narradora con Cíndal, un paciente que se suicida tras habérsele negado la consulta psicoanalítica que exigía desesperado. Este arranque establece una postura de crítica ante el "silencio analítico" (Mercado 8) de las prácticas terapéuticas entre las cuales el psicoanálisis es particularmente desmentido por sus pretensiones científicas incapaces de responder ante la realidad humana. El reproche se extiende desde la práctica correctiva del psicoanálisis hacia toda la estructura social basada en el habitus de la "plenitud" y la "gratificación" que requiere sujetos sanos. ${ }^{4} \mathrm{Al}$ servicio de esa estructura, el psicoanálisis habría perdido su conexión con el individuo, buscando disciplinarlo en lugar de acompañarlo en su libre autofiguración, afirmándose así como dispositivo de biopoder que "atraviesa los cuerpos y graba la norma en las conciencias ... conformando determinados tipos de productores" (Foucault 25-26). Parece que la ruptura está en la base del distanciamiento de la narradora con esta y otras prácticas que legitiman su dominio, naturalizando el malestar de los dominados. No obstante este reconocimiento, la narradora sigue buscando una "existencia como 'caso" (Mercado 13) en esta dinámica reificatoria para "adherir la pobre masa psíquica a estructuras exteriores con el objeto de dotarla de una forma ... buscando en la repetición la manera de evitar la infelicidad" (20).

Esta percepción de institución utilitarista y pragmática marca negativamente su relación con la literatura. Al explicar por qué esta es para ella un "territorio impracticable", a pesar de haber estudiado para ejercer una profesión académica como "ganapán", la narradora refiere que a este "universo de formalizaciones" solo puede acceder quien "logr[a] repetir, aun para un interlocutor ficticio, lo que el libro contiene", por lo que se supone "condenada a mantener una relación secreta y casi confidente con las obras de la inteligencia, pero sin poder valer[se] de ellas como instrumentos de contradicción o de integración en el mundo de las ideas" (140-141; énfasis en el original). Como menciona Marina Kaplan, el gesto que más explícitamente comunica el desprecio de la protagonista por el pragmatismo de la institución literaria es la quema de las notas con que diera clases de literatura en el exilio:

This burning of the notes ... functions ... as a mise en abyme of the text's own constant undoing. What is incinerated is the institutionalization of literature, reminding us through this gesture of the "institutionality of this institution, but of an institution that can only consist in passing itself off as natural" (Derrida, Given Time I 169). We can read the narrator's action as the burning of the institution or of 
her false naturalization. Or of both. In either case, we are dealing with identity papers here. And it is this condition of having no institutional legitimacy that writing assumes at the limit of or beyond literature. (235; énfasis en el original)

La disociación de la escritura del dominio pragmático y referencial de la literatura es todavía más evidente al compararla con el tejido, una labor manual que, en tanto hábito o técnica del cuerpo, pertenece al nivel de la "protomemoria" en la estructura de Candau (11). La narradora refiere:

Hay un grado de abstracción tal en la labor textil que ... la persona desaparece del transcurso natural de cualquier ser en el tiempo ... Esos compartimentos secretos y deshabitados, tierra de nadie, a los que se llega cuando se quiere escribir ... difieren de los paraísos que se rozan con el vuelo textil; son incluso ... de signo opuesto, porque en el recinto de lo textil hay una suerte de felicidad del no-ser y del noestar, mientras que en el de lo textual ... sólo se recoge desventura; y no desventura como un sentimiento personal, sino como expresión de una desnudez fundamental: no saber, no poder llenar el vacío, no abarcar lo universal. (144-146)

La escritura aparece primero como un lenguaje gestual, no referencial, que ofrece el refugio preverbal y pre-ético propio de la protomemoria con sus prácticas atemporales e idílicas, para luego definirse como un paraíso perdido por la propia naturaleza lingüística que fija significados inmanentes (Candau 11).

Paradójicamente, mediante esta textualización conflictiva del carácter material y referencial de la escritura, la voz narrativa comienza a tomar conciencia de su propia búsqueda. Para ello, lejos de parodiar la referencialidad y deconstruirla en tropos, como sugiere Kaplan (235), el sujeto del texto desplaza su interés del tejido a la filosofía, para desde ahí confrontar su propia sed de trascendencia. No en vano el relato dedica a esta instancia teórica el capítulo "Fenomenología", en el que se narra la empresa grupal de leer la Fenomenología de la percepción de Hegel. Esta lectura pone a la narradora en "estado de riesgo" y la lleva a confesar su necesidad "de absoluto, aunque esta palabra tenga un alto costo referencial" (146), como si en el momento de escribir el relato, Mercado fuese ya consciente de que la trascendencia atemporal perseguida en el tejido (por ausencia) y en la filosofía (por exceso) no era otra cosa que el esencialismo de la memoria que, según defiendo, el relato denuncia a posteriori. No obstante, en esas sesiones filosóficas la narradora establece un espacio intersubjetivo en el que la dimensión inabarcable de la pérdida adquiere la escala humana de la amistad en "ceremonias a nuestra medida de una intensa revelación del Espíritu, una epifanía 'filosófica' luego de la 
cual pudimos llegar, de una manera irrepetible, al conocimiento, a un conocimiento" (144). La reinserción del deseo y la satisfacción, ausentes incluso en la revelación del desenlace, ocurre en la ritualización de la experiencia filosófica de la protagonista, que conecta lo colectivo y lo trascendental.

La protagonista pasa igualmente por espacios urbanos en los que el discurso de la memoria cultural (Assmann) toma la forma de museos, bibliotecas y universidades que la voz narrativa visita y que suscriben el carácter político de su búsqueda a referentes marxistas en los que se cuestiona la utopía socialista. En todos esos recorridos de los lugares de la memoria (Nora), la narradora ejecuta nuevos rituales marcados por la puesta en tensión entre una "nostalgia restaurativa" ante la patria desmoronada y la "nostalgia reflexiva" propia del duelo. Svetlana Boym considera que en la coyuntura de estas formas complementarias de nostalgia toma forma "our relationship to a collective home" (41). Según ella, la nostalgia restaurativa, "builds on the sense of loss of community and cohesion and offers a comforting collective script for individual longing" (42). Al espacializar el tiempo, esta permitiría llevar a cabo la función retrospectiva de la alegoría (49). Por el contrario, la "nostalgia reflexiva" se encarga de "temporalizar el espacio" para poner en evidencia "the gap between identity and resemblance" y abrir el pasado hacia "a multitude of ... non teleological possibilities of historic development" (50; énfasis mío), facultando el discernimiento entre un esencialismo histórico que aplasta y el redescubrimiento de nuevos "collective frameworks of memories" (54). Mediante este trabajo de retrospección crítica, el sujeto del texto echaría a andar la función prospectiva y de cohesión social que Avelar, siguiendo a Benjamin, relaciona con el impulso melancólico. Sin embargo, toda nostalgia opera como una facultad de la memoria "de haut niveau, ... de rappel ou de reconnaissance" (Candau 14), en la que afecto y razón construyen estructuras que en su dinámica restitutiva bloquean núcleos conflictivos más profundos. En cambio, la alegoría en tanto mecanismo prospectivo que interviene en el ámbito de la metamemoria sólo se consolida en el momento de la puesta en discurso.

Al final de su pragmática de la memoria, Ricoeur señala lo siguiente: "[L]e pardon ... constitue l'horizon commun de la mémoire, de l'histoire et de l'oubli ... S'il est vrai que la justice doit passer, sous peine que soit consacrée l'impunité des coupables, le pardon ne peut se réfugier que dans des gestes incapables de se transformer en institutions" (Mémoire 593594). Parece adecuado, entonces, proponer que aquello que la narradora articula, al relatar su tentativa de otorgar a todas estas instituciones del saber el estatuto de autoridad capaz de resemantizarla como sujeto, 
involucra una voluntad implícita de perdón, que escapa del alcance de toda práctica humanista o terapéutica, y cuya necesidad le era imposible detectar al enfrentar esas opciones. El relato da una clave para esta interpretación: a su regreso a Argentina, al visitar a una amiga que tenía "un tinglado terapéutico con psicoanálisis freudiano, budismo Zen y camino Tao" (59), la narradora expresa por primera vez su interés por escribir. Aunque la trama lleva al lector a creer que esta toma de consciencia ocurre en el desenlace (con el desvanecimiento alegórico del muro), en esta primera verbalización la escritura se revela no como profesión ligada a una institución dogmática, sino como espacio simbólico de perdón: “Con esfuerzo y luego de una inmersión en mi alma como ante un confesionario, dije que lo que a mí me interesaba era escribir, 'fundamentalmente escribir', dije ... No era otro mi deseo: 'escribir', había dicho yo con la inflexión de quien se hace perdonar por una falta" (6o; énfasis mío). Aunque la argumentación opone su necesidad afectiva al valor mercantil que su interlocutora atribuye a la escritura, es evidente el carácter confesional y la dimensión redentora - de perdón pedido - de esta escena, aunque este diálogo no haya ofrecido en su momento vivencial el empoderamiento identitario que adquiere al ser puesto en relato.

La imposibilidad de dar el salto a la praxis escritural en aquel momento viene dada, a mi parecer, por la dimensión universal que la narradora atribuía a su búsqueda. Más que un perdón, que restablece una relación entre individuos por una ofensa, el campo semántico de la enunciación revela el nivel de imperativo absoluto hacia el que la narradora se siente en deuda. El perdón pertenece a una dimensión que reconoce que "justice is part of the earthly economy" (Mensch 150), mientras que la misericordia es un perdón absoluto, de orden divino y, por ende, imposible. Lo que la escritura restablece, entonces, es la dimensión humana de lo que hasta antes de ser escrito no ha sido una búsqueda de perdón, como en la pragmática ricoeuriana, sino de misericordia. Si bien el término sorprende, en "From Power to Biopower... and back" Slavoj Žižek se interroga:

Is the relationship between law (legal justice) and mercy really the one between necessity and choice? Is it really that one has to obey the law, while mercy is by definition dispensed as a free and excessive act, as something that the agent of mercy is free to do or not to do ... ? What if, with regard to law, we have the freedom to choose (to obey or violate it)? While mercy is obligatory, we have to display it mercy is an unnecessary excess that, as such, has to occur ... Is it not that showing mercy is the only way for a Master to demonstrate his supralegal authority? If a Master were merely to guarantee the full application of the law, of legal regulations, 
he would be deprived of his authority and turn into a mere figure of knowledge ... (This is why even a great judge is a Master figure: he always somehow twists the law in its application by way of interpreting it creatively). (504; énfasis en el original)

Este giro creativo de la ley es lo que la narradora le reconoce a la literatura, haciendo de ella un mejor amo o juez (un "master" a escala humana) para resolver

el dilema del sobreviviente [de la dictadura, que] reside en el carácter inconmensurable e irresoluble de esa mediación entre experiencia y narrativa [en la cual] la organización diegética misma del horror vivido es percibida no sólo como una intensificación del propio sufrimiento, sino, lo que es peor, como una traición al sufrimiento de los demás. (Avelar 282)

Es ese percibirse a sí mismo como traidor lo que busca ser perdonado en la escritura, desprovista de la autoridad intransigente que la narradora atribuye a las instituciones del saber que destituye conscientemente. El psicoanálisis, la práctica académica, los espacios arquitectónicos de registro, preservación y conmemoración cultural, e incluso la filosofía, son finalmente vistos como dispositivos hermenéuticos capaces de facilitar elaboraciones lógicas de los procesos fenomenológicos y de la estructura social, pero carentes de la autoridad performativa y afectiva, humana y falible, que el texto literario conjuga al hacer extensiva, tras su publicación, la experiencia íntima del discurso de la memoria colectiva, bajo la forma de un registro de memoria cultural. ${ }^{6}$

Me parece que aludir al perdón como acto de autorrealización en el espacio simbólico del texto resuelve el distanciamiento entre literatura y escritura dentro de la misma pragmática de la memoria, sin evocar una crisis de representación ni un quiebre racional, como ocurre cuando Moreiras define el texto de Mercado como una

traza teórica entendida como marca mnemónica en el delirio ... [desde la cual] la teoría se abre a la posibilidad de ser captada, autográficamente, no como locus institucional, sino como tensión contraria: y entonces, como lugar destitucional, si insiste en su propia negatividad, o como lugar restitucional, si insiste en su positividad potencial. (391)

La mención del "delirio" inscribe este relato altamente racionalizado en el campo de la sinrazón. ${ }^{7}$ Para evitar caer en una posible escisión entre una literatura que razona y otra que delira, parece acertado señalar con 
Annette Levine que "Mercado performs reconciliation and mourning within her body of writing. Her writing ... [is] a 'live' performance, one that she acted upon in order to externalize her experience ... The reader becomes witness to Mercado's experiences and her metaexternalization of trauma" (113). Esta escritura performativa (praxis), en el doble sentido de puesta en escena y acto de habla, constituye, a mi parecer, la fuerza expresiva (afectiva) y crítica (política) del relato. En este sentido, coincido con Kaplan, quien afirma que:

Such poetry does not litigate directly. It does not speak the language of the institution or the state ... It enables the deconstruction of the hierarchical opposition between hegemonic sense (realism) and subaltern non-sense ... [W] riting avoids imaginary representation or narcissistic identification and disrupts what Roland Barthes had called the bad faith of the first-person narrative (Writer Sollers 46). From this point on, we suspect that we will no longer be writing about a story or a self, both pretexts, but about a practice. (225-226)

Podemos concluir que, por encima de cualquier restitución o duelo, la performance textual de Mercado es una poética del détournement que pone en escena la destitución de la literatura en tanto institución de la memoria, aferrándose a la escritura como práctica intempestiva. ${ }^{8}$

EL IMPULSO REVOLUCIONARIO DE LOS TOPOS

El segundo epígrafe de este artículo remite al aspecto unánimemente celebrado por la crítica de Los topos: la ruptura formal con que, en palabras de Beatriz Sarlo, esta "novela cómica, fantasiosa ... cuyos desvíos interesan más que la trama ... ha cerrado una etapa" en la manera de percibir y transmitir el tema grave de las secuelas que dejara la última dictadura argentina (1976-1983) (Condición 2). ${ }^{9}$ Dicha etapa comenzaría en los primeros años de redemocratización y estaría caracterizada por un imperativo moral que habría impedido la emergencia de registros "distintos a [la] evocación subjetiva, el non fiction, la alegoría o el realismo" (3). La ruptura formal respondería a una serie de actos reivindicativos vinculados al contexto sociopolítico que, admite Sarlo, "no marcan directamente la literatura pero crean condiciones de escritura" (Condición 2). ${ }^{10}$ Tres años antes, la propia Sarlo denunciaba la falta de distancia crítica vinculada al "giro subjetivo" de la "cultura de la memoria": un "reordenamiento ideológico y conceptual" que operaba sobre la falsa premisa de que es posible "entender el pasado desde su lógica (una utopía que ha movido a la historia)", y que promovía "la confianza en la inmediatez de la voz y del cuerpo[,] favorec[iendo] al testimonio" frente a 
otros discursos "de los que la primera persona está ausente o desplazada" (Tiempo 20-23). En tanto miembro de la llamada "generación de la postmemoria", Bruzzone estaría demandando una lectura ajena a la perspectiva de las víctimas coetáneas al momento traumático." Su humor sería una forma de "postmemoria afiliativa", en términos de Marianne Hirsch, capaz de establecer vínculos afectivos más allá de la comunidad cultural de referencia (Sosa 77 ). ${ }^{12} \mathrm{Si}$ bien el humor puede ser clave en la transmisión empática de hechos históricos a nuevas audiencias, ningún "quiebre generacional en lo literario" (Hernando 7) depende únicamente de un rasgo formal, ni se explica desde marcos contextuales o aludiendo a su potencial performativo. Dichas lecturas dejan sin respuesta la cuestión más relevante: ¿Cómo la novela de Bruzzone activa en el lector la función crítica que los registros subjetivos alejados de la ficción inhiben? ¿0 acaso su mérito se reduce a promover el olvido colectivo, parodiando las secuelas de la dictadura?

El recurso a una serie de metáforas que pueden ser interpretadas de manera equívoca al menos en dos niveles de significado es la definición misma de la alegoría. En mi lectura, la ironía y la autoficción son sólo dos mecanismos retóricos que esta metaficción historiográfica en clave alegórica emplea en la cadena de signos de doble código que apenas comienza con el equívoco identitario que el autor presta al narrador protagonista sin nombre. ${ }^{13} \mathrm{El}$ recurso generalizado al equívoco se extiende a los personajes que, al ser resemantizados en sus nombres ("la abuela Lela", "el Alemán", los muchos "topos"), en sus cuerpos (travestismo, prostitución, implantación de senos) y en sus acciones (huir, buscar al hermano perdido, secuencia de despojos, perseguir la venganza, enamorarse del represor, desaparecer en el paisaje blanco), se deben leer como símbolos. Aquí, autor y discurso asumen su identidad emblemática y parodian la búsqueda de la memoria herida por (no de) los padres. Su acercamiento no es el de la reivindicación emblemática de la memoria, sino del olvido. A mi parecer, es este doble código alegórico - la ironía como contradicción al discurso dominante en torno a la memoria y la puesta en evidencia de la (auto)ficción como espacio alternativo y desestabilizador de toda construcción subjetiva - lo que permite a Los topos denunciar la autoridad de la memoria como imperativo epocal y ofrecer claves en torno a aquello que impide al escritor contemporáneo asumir la función política que ineluctablemente el texto realiza en su dimensión performativa. ${ }^{14}$ Todo ello ocurre sin descuidar otras funciones propias de la alegoría, como la evocación retrospectiva (ya sea nostálgica o melancólica) y la imaginación prospectiva (ya sea utópica o apocalíptica), que median en la elaboración afectiva e ideológica. 
La negativa de Los topos a realizar el duelo se materializa en la oposición del protagonista a las instituciones de restitución de la memoria de las víctimas y sus familiares. A lo largo de la trama, el protagonista sufre la pérdida de figuras familiares, casas, documentos, profesión, propiedades y señas de identidad. Su trayectoria de Buenos Aires a Bariloche comienza con la búsqueda de Maira, travesti y supuesto hermano nacido en cautiverio, pero se convierte en "reivindicación realista" (Hernando) o "fantasía de venganza" (Sarlo, Condición 3) individual y colectiva que la crítica ha tendido a leer como un desplazamiento del aparato represor del pasado dictatorial hacia las formas contemporáneas de totalitarismo. Al descubrir que Maira ha sido asesinada por el Alemán, ex-represor de la dictadura que ella perseguía, el protagonista, travistiéndose a su vez, encarna la misión vengativa. Sin embargo, en giro irónico de la trama, se enamora del Alemán y termina sometido a sus demandas abusivas. Su negativa a reescribir el relato colectivo de la memoria herida resultaría en un borramiento identitario y en la imposibilidad de reconectar con lo social y lo político (Hernando; Portela; Ros; Allende y Quiroga):

La novela no sólo no llama a la acción política sino que señala la falta de opciones para resolver la devastación de un presente brutal que ha nacido de un pasado brutal. El hecho de que el narrador y protagonista desaparezca sin dejar rastro hace al lector asumir que la búsqueda que inició como alternativa reconstructiva de una identidad acaba en total (auto)destrucción. Tal vez Bruzzone intenta presentar una nueva poética de significado ... pero la promesa de significado e identidad se travestiza ... El cuerpo travestido del protagonista disloca la narrativa histórica familiar de la identidad y reterritorializa la geografía nacional para convertirla en una geografía propia ... que acaba no sólo en fracaso, sino en desaparición. La principal contrariedad que presenta su narrativa es que, en contraste con el discurso político de grupos como H.I.J.O.S, que llaman a la acción directa y la reivindicación, Bruzzone nos deja perdidos y sin recursos en un mundo violento, grotesco e incomprensible, cuya interpretación total es imposible. (Portela 182-183; énfasis mío)

La mención de la totalidad es crucial para establecer la demanda implícita de cierta crítica hacia una novela cuya elaboración del pasado y del presente consiste precisamente en denunciar toda posible "promesa de significado e identidad" ligada a la "totalidad". Al igual que Mercado, Bruzzone recurre al discurso literario como autoridad legítima e intempestiva desde la cual denunciar la invalidez de otros discursos totalitarios. Si la performance literaria de Mercado deja a su paso "paper cemeteries" (Levine 111), Bruzzone propone "quemar", "travestir" o 
"enterrar" esos cementerios y otros lugares de la memoria que el imaginario social y las instituciones del recuerdo han promovido. Al enunciarse directamente en el espacio restitucional de la ficción, autor y novela evitan enredarse en el escollo impuesto a la identidad subjetiva por el estatuto institucional de la literatura. Pero resulta irónico que esa función restitutiva de la literatura sea precisamente lo que Bruzzone no reconoce. Según refiere en una entrevista: "Yo nunca milité en H.I.J.O.S. ... no necesitaba hacerlo. A mí no me interesa hacer algo reivindicativo, la literatura no sirve para eso. La literatura tiene que cuestionar y mostrar tensiones; trabaja más en la dimensión de la representación ... [C]omo escritor no me interesa tomar partido" (Friera). Queda claro que la literatura se define en oposición a H.I.J.O.S., entendido como espacio de reivindicación estrictamente sociopolítico, incapaz de ofrecer distancia crítica, disenso ni - lo que, a mi parecer, es decisivo en la articulación textual de Los topos - restitución afectiva y reconocimiento individual, condiciones necesarias para legitimar el dominio autoritario que el protagonista persigue a lo largo la trama.

En tanto construcción alegórica, la novela opera simultáneamente en dos niveles. La trama plantea una trayectoria afectiva que se modifica al incorporar la voluntad ajena de venganza. La novela comienza evocando la nostalgia, más restaurativa que reflexiva, que la "abuela Lela" invierte en la fantasía del "otro nietito", supuestamente nacido durante el cautiverio de la madre en la ESMA. Al morir el abuelo, Lela vende "la casa de Moreno" y se mudan a un departamento con "perfecta vista a la ESMA" cuya "zona, sin zanjas, sin grillos, sin sapos," priva al narrador del refugio imaginario desde el cual espiaba las discusiones de los abuelos sobre el hermano desaparecido, la madre asesinada y el padre traidor (11-13). Más que vengar a los padres, el protagonista busca concluir el duelo de la abuela destruyendo el sustrato material que lo sustenta, que es a la vez el epicentro simbólico del trauma y el lugar de la memoria institucionalizado en la forma monumental de un museo que recibe el tratamiento artificioso que un melancólico da a sus síntomas: "la presencia constante de la ESMA ... los canteros llenos de flores que de tan perfectas parecían de papel. A veces hasta me daban ganas de seguir a mi abuela en su historia delirante y salir a incendiar los jardines o demoler el edificio a patadas" (13). Significativamente, su fuga comienza de cara al imperativo melancólico de la ESMA, pero se extiende a todo el espacio público de Buenos Aires: "las luces de la ciudad nos perseguían y por momentos podía parecer que nos escondíamos de ellas, que nos escapábamos, porque siempre terminábamos en lugares oscuros ... contrafrentes de grandes edificios públicos" (14). Esta inconfesable paranoia lo lleva a buscar compañía 
efímera que abandona tras "inventa[r] historias ... mentiras" que "olvid[a] rápido" para "nunca habla[r] de mamá" (15). El fantasma de la orfandad emerge explícitamente al final del primer episodio, como sustrato afectivo de la fuga. Pero en lo sucesivo, la restitución de la memoria herida queda desplazada, por arte de alegoría, a la búsqueda de amor cifrada en la trama detectivesca.

El siguiente episodio narra su relación con Romina, quien lo insta a afiliarse a H.I.J.O.S. y a asumir la paternidad de su hijo. Esta doble afiliación es la única oferta de comunidad y reconocimiento identitario que se le presenta al protagonista en toda la novela. No solo no está fuera del marco del imperativo melancólico, sino que está definida por él, por lo que queda inmediatamente descartada. ${ }^{15}$ Si desde la perspectiva del sentido común " $[t]$ here is certain agreement that in being recognized, our freedom and individuality shine forth, unbound of all the chains that history, violence, and culture weaved around us" (Legrás 19), el reconocimiento que ofrece H.I.J.O.S. no es el que hace honor a su individualidad, sino al fardo social y familiar que, en su perspectiva, le ha negado la libertad de autofigurarse:

'[E]quality before the other' ... implicitly oppose[s] to ... 'equality before the law.' (Taylor, Politics of Recognition 25) [which] continues to be ... an active force in politics and society, but only as negativity ... The trope of 'natural rights' ... impl[ies] that individuals pre-exist and transcend the society that has created them ... In spite of all its current prestige, the promotion of recognition has an ironic and untimely ring to it. Far from being a new development, the present recognition of recognition simply brings to the foreground one ideological kernel of the expansion of modern capitalism. Recognition always turns out to be recognition of a property. (As Hegel unwillingly suggested, there is nothing to be recognized in the juridical figure of a real slave). (Legrás 20-21; énfasis mío)

Al igual que el edificio de la ESMA convertido en museo, H.I.J.O.S. institucionaliza el patetismo de los hijos, convirtiéndolos en emblemas de la memoria social herida. El rechazo de esta asociación - a nivel intra y extradiegético - es, pues, una negación a convertirse en emblema dentro de una estructura agónica que requiere víctimas para subsanar públicamente su necesidad colectiva de conmemoración, perdón y olvido. Las múltiples ironías que la novela construye al mencionar una asociación "nueras", "sobrinas", o una renovada categoría de "postdesaparecidos" y "neodesaparecidos" son otros rasgos de esta destitución del reconocimiento institucionalizado. La exigencia de asumir la normatividad dominante e, incluso, heredarla desata abiertamente lo que propongo denominar el "impulso revolucionario" del protagonista. Es justamente la 
amenaza de verse reificado, asumido como propiedad del sistema que denuncia, lo que motiva la cadena de somatizaciones que, disfrazadas de venganza "justa", pervierten su búsqueda afectiva.

Como en Mercado, la suya es fundamentalmente una búsqueda de reconocimiento identitario y autoridad normativa externa que cumpla la doble función afectiva y rectora que a él le han sido negadas por su orfandad. En este caso, todo posible marco libremente elegido como referente es interpretado en dos niveles: como objeto de pasión (convirtiendo el protagonista en amante, apropiando sus móviles y encarnando su deseo); y como agente represor (de abandono, traición o abuso). Mediante esta dinámica afectivo-autoritaria, la trama plantea dos momentos de quiebre, giros irónicos en torno al cuerpo como signo, que dividen la novela en dos partes, dos territorios geográficos y dos travestismos. El primer giro ocurre en Buenos Aires, cuando el protagonista se enamora de Maira, en cuyo cuerpo travestido y sediento de venganza convergen simbólicamente las figuras familiares perdidas: se parece al protagonista, es el hermano añorado por Lela, es femenino y tierno como la madre, asertivo y traidor como el padre. Maira lo deja para ocuparse de vengar represores infiltrados, pero al cabo de tres días, diríase que la resucita al encarnar su travestismo y autoasignarse su misión de justicia por mano propia. El segundo giro ocurre en Bariloche, adonde el protagonista llega con Mariano, otro hijo de desaparecida con quien vive y trabaja como albañil hasta que lo abandona para fundar una secta panteísta con una chica abusada. Nuevamente solo, asesinar al Alemán constituye el móvil de la segunda parte. Significativamente, en su profunda carencia afectiva, el protagonista se enamora del Alemán, admite horribles vejaciones y accede, sin desearlo, a una implantación de senos. La novela concluye con un lamento de este cuerpo fársico, definitivamente sometido, que espera la muerte entre el lujo mercantil (piscina, dos enanos sirvientes) y la desolación del paisaje nevado.

Parece claro que la relación entre el Alemán represor y el topo-travesti libremente sometido sobrepasa la alusión al totalitarismo nacionalsocialista que, leída como gesto de "memoria multidireccional" (Rothberg), construye una metáfora solidaria entre el presente argentino y la Shoah. ${ }^{16}$ No obstante, más que exigir la ruptura del círculo vicioso entre amo y esclavo, o condenarla, la novela alegoriza una dialéctica social caracterizada por cuerpos que dominan y cuerpos dominados en la que los primeros persiguen invariablemente alguna agenda esencialista que justifica el abandono, la traición y el recurso a la violencia, y los segundos eligen ser victimados. Para elaborar en torno al enigmático impulso que sostiene esta dinámica, recurro primero a Debord: 
L'organisation révolutionnaire ne peut être que la critique unitaire de la société, c'est-à-dire une critique qui ne pactise avec aucune forme de pouvoir séparé ... Dans la lutte de l'organisation révolutionnaire ... les armes ne sont pas autre chose que l'essence des combattants mêmes : l'organisation révolutionnaire ne peut reproduire en elle les conditions de scission et de hiérarchie qui sont celles de la société dominante. Elle doit lutter en permanence contre sa déformation dans le spectacle régnant. (78; énfasis mío)

El protagonista emprende el travestismo en un impulso revolucionario que lo empuja a luchar contra la deformación (la falta de reconocimiento individual por el esencialismo de la memoria) del espectáculo dominante. Pero si en Maira el travestismo es una forma de filtrarse desde lo marginal e íntimo hasta lo institucional siniestro; el travestismo del protagonista no es el mismo que en Maira. Encarnar las figuras de afecto y autoridad perdidas equivale a una perpetua somatización, metáfora de una melancolía irresuelta en la que el yo se identifica con el síntoma y su existencia se limita a garantizarle subsistencia. Así, lo que en Maira es tentativa heroica, en el protagonista es simulacro y síntoma. Su empresa revolucionaria se frustra desde el momento en que, en palabras de Debord, "reproduce en sí mismo y en sus actos las condiciones de separación y jerarquía del dominio totalitario que combate". Al buscar justicia por mano propia, su acto reivindicativo personal (afectivo) se pervierte, convirtiéndose en esencialismo (venganza, fin que justifica violencia), no solo porque suscribe las formas del dominio totalitario que buscaba subvertir, sino porque, estrictamente, dicha lucha no es la suya, sino un mimetismo del espectáculo que aparece más justo y socialmente validado, como dan cuenta las numerosas fantasías heroicas relatadas. Como afirma Žižek: "In this purely formal act of freely willing, of assuming, as the result of one's free decision, what is in any case brutally imposed on the individual as an inevitable necessity, resides the elementary gesture of subjectivation" ("Antigone" 51; énfasis mío). Así, el triunfo del dominio totalitarista solo se le hace evidente al protagonista una vez incorporadas las reglas del espectáculo en su cuerpo sometido. Ahora bien, ¿cómo puede leerse esta búsqueda de esclavitud voluntaria como acto subversivo o revolucionario? ¿Dónde radica su potencial crítico?

Si consideramos la metáfora de la encarnación del síntoma a un nivel alegórico todavía más alto, podemos leerla como carnavalización del cuerpo que interrumpe momentáneamente el dominio totalitario para luego ceder a su influjo y ser eliminado. En su análisis de los cuatro discursos lacanianos, Žižek explica que, al final de El estado de excepción, Giorgio Agamben "imagines two Utopian options of how to break out of the 
vicious cycle of law and violence, of the rule of law sustained by violence. One is the Benjaminian vision of 'pure' revolutionary violence with no relationship to the law" - opción que remite al impulso revolucionario de Maira - "[t]he other is the relationship to the law without regard to its (violent) enforcement" -alternativa que lleva al impulso revolucionario del protagonista. Y continúa Žižek:

Agamben starts from the right insight that the task today is not synthesis but separation, distinction: nor bringing law and violence together (so that right will have might and the exercise of might will be fully legitimized), but thoroughly separating them, untying their knot ... [S] uch a gesture of separation is what the Hegelian 'synthesis' is effectively about. In it, the opposites are not reconciled in a 'higher synthesis'; it is rather that their difference is posited 'as such'. ("Lacan's")

La búsqueda del protagonista puede ser leída ahora como una tentativa de romper ese "círculo vicioso de la ley sostenida por la violencia" para encontrar un amo justo, alegorizada en la cadena de somatizaciones, cuyo objetivo se va distorsionando.

El cuerpo del protagonista se convierte así en el territorio de disputa entre varios discursos de autoridad, no porque estos quieran apropiarse de él, sino porque él mismo se ofrece como locus interpretativo del deseo del otro y de sus luchas, hasta quedar fatalmente sometido. Toda posible identidad afectiva e intersubjetiva desaparece bajo el totalitarismo biopolítico. A este nivel, el cuerpo ya no es signo de una subjetividad colectiva disfórica y destituida, sino imagen ejemplificadora de sus consecuencias, alegoría del cuerpo político pervertido. En él no hay resonancias de comedia ni humor, y su figura trágica encarna todo el linaje del autoritarismo violento, precursor de toda dictadura, del que son herederos los múltiples esencialismos contemporáneos. Teniendo esto en cuenta, Los topos es una alegoría de la lucha entre la voluntad de una ley (humanista) justa y la violencia con que la ley (soberana) justifica su dominio en el Estado de excepción. ${ }^{17}$ Es también una alegoría de la lucha íntima que implica "la posibilidad misma de distinguir vida y derecho" (Agamben 157). La imagen final remite a esta indiferenciación como prefiguración apocalíptica y, como tal, preventiva y crítica. Bruzzone no da una fórmula para separar la violencia del derecho y orientar al lector hacia la restitución política. Ofrece, en cambio, una metáfora de dicha identificación en términos de orfandad social y afectiva. A pesar del bloqueo momentáneo de la capacidad reivindicativa de la literatura que el autor efectúa durante la escritura, el cuerpo del protagonista, con sus senos implantados como sello de sometimiento a la violencia de la ley 
injusta, es también una metafórica madre de la Plaza de Mayo (Sosa 86), imagen conmemorativa que contradice la tentativa del détournement inicial del carácter reivindicativo de la literatura, confirmándola como discurso político en su dimensión performativa.

Podemos concluir que, a una generación de distancia y pese a la restitución o destitución subjetiva de sus tramas, tanto En estado de memoria como Los topos ponen en escena una doble elaboración alegórica: entre identidad y memoria, y entre el sujeto del texto y la autoridad institucional del discurso memorioso. Se trata, pues, de un ejercicio intempestivo, una rebelión contra las prácticas institucionalizadas de la memoria coetánea, percibidas como dispositivos biopolíticos encaminados a generar un consenso socialmente productivo en el que la memoria herida solo obtiene el reconocimiento antagónico y agónico de la víctima, sin poder dejar de serlo. Dicha elaboración es dialógica, pues la trama parte de una oposición dialéctica, genera tensiones y eventualmente desautoriza dichas prácticas. En ambos relatos, lo que la búsqueda y la escritura persiguen de manera explícita o alegorizada no es la mera superación o representación del duelo íntimo o colectivo, sino la creación de una forma alternativa y personal de abordar la memoria como discurso inestable. Para reinsertar el reconocimiento afectivo que ofrece la literatura en tanto práctica cultural y autoridad de la metamemoria, ambos relatos realizan una disociación momentánea de la escritura en tanto práctica subjetiva no institucionalizada.

University of Ottawa

\section{NOTAS}

$1 \quad$ Esta es la definición de Debord: "Le détournement est le contraire de la citation, de l'autorité théorique toujours falsifiée du seul fait qu'elle est devenue citation; fragment arraché à son contexte, à son mouvement, et finalement à son époque comme référence globale et à l'option précise qu'elle était à l'intérieur de cette référence ... [C']est le langage fluide de l'anti-

idéologie. Il apparaît dans la communication qui sait qu'elle ne peut prétendre détenir aucune garantie en elle-même et définitivement. Il est, au point le plus haut, le langage qu'aucune référence ancienne et supra-critique ne peut confirmer. C'est au contraire sa propre cohérence, en lui-même et avec les faits praticables, qui peut confirmer l'ancien noyau de vérité qu'il ramène. Le détournement n'a fondé sa cause sur rien d'extérieur à sa propre vérité comme critique présente" (126). 
2 Efectivamente, Kaplan afirma que "En estado de memoria has been read as a novel (Franco), as fragmented memoirs and a testimonial novel (Avelar), as a novel, autobiographical fiction, and personal testimony ( $\mathrm{O}^{\prime} \mathrm{Connell}$ ), and as an example of the subgenre of the 'criolla gender essay' (Castillo 106-107). Other readings thematize exile within the genre of autobiography" (235).

3 Moreiras utiliza el término "destitucional" para referir que se destituye lo institucional.

4 La narradora expresa lo siguiente a propósito de la muerte de Cíndal: "[s]e lo dejó morir porque ... reclamos de ese tipo no hacen más que oscurecer la vida de los demás y socavar la plenitud a la que todos tienen derecho. Nadie que viva en conformidad, lleno de proyectos y certezas, nadie que reciba constantes gratificaciones puede bajar la guardia y dejar entrar a gente como Cíndal..." (5-8).

5 Avelar sostiene que el de Mercado "es un texto escrito ... como un desmontaje crítico" de lo que Hugo Achugar llama "la mala conciencia" de aquellos que, tras "la catástrofe de la dictadura" prefirieron "vivir con la culpa antes que arriesgarse a obtener justicia” (284).

6 Para Assman, la memoria cultural constituye la tradición y la identidad diacrónica, tiene carácter institucional y está siempre mediada por textos, rituales y un lenguaje formalizado (117): "Cultural memory reaches back into the past only so far as the past can be reclaimed as 'ours' ... Knowledge about the past acquires the properties and functions of memory if it is related to a concept of identity. While knowledge has no form and is endlessly progressive, memory involves forgetting. It is only by forgetting what lies outside the horizon of the relevant that it performs an identity function" (113). Su intensidad genera 'comunidades afectivas' (Halbwachs): “One has to remember in order to belong" (114).

7 Aunque no explicita sus fuentes, parece que Moreiras entiende el "delirio" en el sentido de Deleuze y Guattari en el Anti Edipo. Capitalismo y Esquizofrenia: no como una patología, sino como un límite liberador de la "máquina deseante" en el que se realiza el deseo. De acuerdo a Deleuze: "le délire est ... investissement d'un champ social historique ... Ca veut dire que le délire, c'est cet espèce d'investissement, c'est cet espèce d'investissement par le désir du champ historique et social" (Cours; énfasis mío). La escritura, en tanto textualización del deseo, sería una forma de delirio capaz de trastocar el status quo.

8 Con Nietzsche, denomino "intempestivo" al olvido momentáneo del presente de la acción en oposición al historicismo como mal de época (72). En este sentido, lo "intempestivo" no está fuera del tiempo, sino que opera $a$ contracorriente de su tiempo.

9 Para Sarlo, Los topos mezcla "realismo autobiográfico, costumbrismo, realis- 
mo político, evocación, parodia, grotesco, novela policial ... casi una comedia de equivocaciones [a] unque también una comedia romántica” (Condición 3).

10 Sarlo menciona "la recuperación de decenas de hijos de desaparecidos por las Abuelas; la activación de HIJOS ... la continuación de los juicios a los terroristas de Estado ... la restitución misma del edifico de la ESMA" (Condición 1).

Propuesta por Marianne Hirsch en 1997, la noción de "postmemoria" originalmente refería una situación comunicativa de transferencia intra- e inter-generacional que involucraba la memoria de los hijos de víctimas de eventos traumáticos con el objetivo de discernir entre una memoria derivada de la vivencia y una (post)memoria mediada por múltiples modos de transmisión. Uno de los ataques más importantes a esta noción sostiene que, al centrar su atención en el momento traumático, la memoria de las víctimas adquiere prioridad por encima de la de los hijos, relegando su experiencia a una posición secundaria (Blejmar y Fortuny; Sarlo, Tiempo). El término prioriza la inversión afectiva sobre la intención de verdad, pues establece una diferencia fundamental entre la operación cognitiva que media entre las víctimas directas del evento traumático y sus descendientes, cuya posición enunciativa excluye a priori la posibilidad de plantearse un pacto de veracidad, pues el pasado no viene "actually mediated by recall but by imaginative investment, projection and creation" (Hirsch 107). Los topos es indudablemente un relato de postmemoria por tratarse de un "discurso donde queda implicada la subjetividad de quien escucha el testimonio de su padre, de su madre, o sobre ellos" (Sarlo, Tiempo 132).

12 En este sentido, Sosa afirma lo siguiente: "[T] he engagement of new generations with humour has managed to add something new to the experience of loss. Humour has not only provided a means of political empowerment for those who have been persistently constructed into victimizing categories. Rather, it has become the surface and medium of an experience of iteration, displacement and contagion. While subverting and mocking traditional bloodline scripts, humour has propitiated a process of transference across wider audiences. In so doing, the expansive and embodied resonances of the comical have showed how traumatic memories can also be adopted by others" (77).

13 Para Linda Hutcheon, "Historiographic metafiction works to situate itself within historical discourse without surrending its autonomy as fiction. And it is a kind of seriously ironic parody that effects both aims: the intertexts of history and fiction take on parallel (though not equal) status in the parodic reworking of the textual past [that] manages to satisfy ... desire for 'worldly' grounding while at the same time querying the very basis of the authority of that grounding" ("Historiographic" 3-5; énfasis mío).

14 Linda Hutcheon propone que "There is nothing intrinsically subversive about 
ironic scepticism or about any such self-questioning, 'internally dialogized' mode (LaCapra 1985: 119); there is no necessary relationship between irony and radical politics or even radical formal innovation (Nichols 1981: 65). Irony has often been used to reinforce rather than to question established attitudes (cf. Moser 1984: 414), as the history of satire illustrates so well" (Irony's 10; énfasis en el original).

15 Para una referencia a la "identidad definida" que otorga H.I.J.O.S. véase Allende y Quiroga, 11.

16 El modelo teórico de "multidirectional memory" de Rothberg propone que la apropiación y reconocimiento de la memoria del Holocausto por comunidades memoriosas ajenas o distantes a las vinculadas en el hecho histórico potencia y promueve el reconocimiento de otras historias locales de dominio, lejos de negarlas o competir con sus memorias: "Instead of memory competition ... multidirectional memory ... is meant to draw attention to the dynamic transfers that take place between diverse places and times during the act of remembrance ... [It] allows for the perception of the power differentials that tend to cluster around memory competition, but it also locates that competition within a larger spiral of memory discourse in which even hostile invocations of memory can provide vehicles for further, countervailing commemorative acts. [It also] posits collective memory as partially disengaged from exclusive versions of cultural identity and acknowledges how remembrance both cuts across and binds together diverse spatial, temporal, and cultural sites" (10-11).

17 A propósito del Estado de excepción, Agamben revela que: “Del estado de excepción efectivo en el cual vivimos no es posible el regreso al estado de derecho ... Pero si es posible intentar detener la máquina, exhibir la ficción central, esto es porque entre violencia y derecho, entre la vida y la norma, no existe ninguna articulación sustancial ... En el campo de tensión de nuestra cultura actúan dos fuerzas opuestas: una que instituye y pone y una que desactiva y depone. El estado de excepción es el punto de su máxima tensión y, a la vez, lo que al coincidir con la regla hoy amenaza con volverlos indistinguibles. Vivir en el estado de excepción significa tener la experiencia de ambas posibilidades y aun así intentar incesantemente, separando en cada ocasión las dos fuerzas, interrumpir el funcionamiento de la máquina ... biopolítica ... Pero el desencanto no restituye al encantado a su estado originario: según el principio por el cual la pureza no está nunca en el origen, éste sólo le da la posibilidad de acceder a una nueva condición" (156-157).

OBRAS CITADAS

AgAmben, gi orgi o. Estado de excepción. Homo sacer II. Trad. Flavia e Ivana 
Costa. Buenos Aires: Adriana Hidalgo Editora, 2005.

ALlende, SANTiAgo y guSTAVo quiRoga. "Representaciones del pasado reciente. Memorias encontradas y búsqueda identitaria en la generación de hijos de militantes de los años 70". Actas de las Primeras Jornadas de Historia Reciente del Noroeste Argentino. Tucumán: AHONA, 2010. I-22. Web.

AR F U CH, LEON OR. Memoria y autobiografía. Exploraciones en los límites. Buenos Aires: Fondo de Cultura Económica, 2013.

as sman n, JA N. "Communicative and Cultural Memory". Cultural Memory Studies. An International and Interdisciplinary Handbook. Eds. Astrid Erll y Ansgar Nünning. Berlin-New York: Walter de Gruyter, 2008. I09-ıI7.

AVE LAR, I D L B R. Alegorías de la derrota: la ficción postdictatorial y el trabajo de duelo. Santiago: Cuarto Propio, 2000.

BENJAM IN, WALTER. "El autor como productor". Tentativas sobre Brecht: Iluminaciones III. Pról. y trad. Jesús Aguirre. Madrid: Taurus, I998. II7-I34. BLEJMAR, JORDANA AND NATALIA FORTUNY. "Introduction". Journal of Romance Studies 13.3 (2013): $\mathrm{I}^{-5}$.

в о ум, SV E t LANA. The Future of Nostalgia. New York: Basic, $200 \mathrm{I}$. BRUZZOne, fÉLIX. Los topos. Buenos Aires: Mondadori, 2008.

CANDAU, JoËL. Mémoire et identité. Paris: Presses Universitaires de France, 1998.

DAVID OVICH, KARIN. "Memorias en femenino: testimonios de mujeres sobrevivientes de la dictadura argentina". Diss. Vanderbilt University, 2014. D E B O R D, G U Y. La Societé du Spectacle. Paris: Gallimard, I992.

DELEuZE, GiLles. "Cours de Gilles Deleuze à Vincennes: 'Anti-CEdipe et autres réflexions'”. Transcribed by Frédéric Astier. La voix de Gilles Deleuze en Ligne 27 mayo 1980. S. pag. Web.

Deleuze, gilles y fÉlix guat tari. El Anti Edipo. Capitalismo yesquizofrenia. Trad. Francisco Monje. Barcelona: Paidós Ibérica, 1985.

foucault, michel. Microfísica del poder. Trad. Julia Varela. Madrid: La Piqueta, I992.

FR IE RA, SiLvina. “Cómo rastrear el pasado con las letras". Entrevista a Félix Bruzzone. Página 12 I2 septiembre 2008. S. pag. Web.

HERNANDO, ANA MARÍA. "La búsqueda de identidad en la novela del escritor argentino Félix Bruzzone, Los topos". Actas del IX Congreso Argentino de Hispanistas, La Plata, 27-30 abril 20Io. S. pag. Web.

hiRSCh, MARIAnNe. "The Generation of Postmemory." Poetics Today 29.I (2008): IO3-I28.

HUTCHEON, LINDA. "Historiographic Metafiction. Parody and the Intertextuality of History". Intertextuality and Contemporary American Fiction. Eds. P. O'Donnell y Robert Con Davis. Baltimore: Johns Hopkins UP, 1989. 3-32. 
—. Irony's Edge. The Theory and Politics of Irony. New York-London: Routledge,

I994.

JARA, SANDRA. "Escribir(se) fuera de los límites. Sobre En estado de memoria de Tununa Mercado". Cuadernos del CILHA 7-8 (2005-2006): 157-167. Web.

KA PLAN, MARINA. "Reading an Absent Sense: Tununa Mercado's En estado de memoria". Comparative Literature 58.3 (2006): 223-240.

LEGRÁS, H ORACIO. "Literature, Subjection, and the Historical Project of Latin American Literature". Literature and Subjection. The Economy of Writing and Marginality in Latin America. Pittsburg: Pittsburg UP, 2008. 1²3.

Levine, annet te. "Tununa Mercado's Paper Cemeteries". Cry for me, Argentina: The Performance of Trauma in the Short Narratives of Aída Bortnik, Griselda Gambaro, and Tununa Mercado. Cranbury: Rosemont Publishing, 2008. III-I44. MEN SCH, JA MES R. "Forgiveness and Incarnation". Embodiments. From the Body to the Body Politic. Illinois: Northwestern UP, 2009. I48-156.

mercado, tununa. En estado de memoria. Buenos Aires: Ada Korn, 2000. Moreiras, Alberto. "La traza teórica en Tununa Mercado". Tercer espacio: Literatura y duelo en América Latina. Santiago: LOM-Universidad ARCIS, I999. 389-397.

NIETZSCHE, FEDERICO. "De la utilidad y los inconvenientes de los estudios históricos para la vida". Consideraciones Intempestivas. Obras Completas. Tomo 2. Madrid: Aguilar, 1932. 71-156.

NORA, PIERRE. Les lieux de mémoire. Paris: Gallimard, 1997.

PORTELA, M. EDURNE. “'Como escritor, no me interesa tomar partido': Félix

Bruzzone y la memoria anti-militante." Contracorriente 7.3 (2010): I68-I84. Web.

RIC O U R, PAUL. La mémoire, l'histoire, l'oubli. Paris: Seuil, 2000.

—. Sí mismo como otro. Trad. Agustín Neira Calvo. México: Siglo XXI, 1996.

Rо тH B RG, MichAE L. Multidirectional Memory: Remembering The Holocaust In The Age Of Decolonization. Standford: Standford UP, 2009.

Ros, ANA. "Los topos de Félix Bruzzone: travestis y traidores contra la realización simbólica del genocidio en Argentina". Confluencia: Revista Hispánica de Cultura y Literatura 29.2 (2014): 92-105.

SARlo, BeAtriz. Tiempo pasado. Cultura de la memoria y giro subjetivo. Buenos Aires: Siglo XXI, 2005.

—. "Condición de búsqueda. Sobre Los topos de Félix Bruzzone". Diario Perfil 7 de diciembre de 2008. S.pag. Web.

SoSA, CECILIA. "Humour and the Descendants of the Disappeared: Countersigning Bloodline Affiliations in Post-dictatorial Argentina". Journal of Romance Studies I3.3 (2013): $75^{-8} 8$.

ŽıŽE K, SLAVOJ. "From Antigone to Joan d'Arc". HELIOS 3I.I-2 (2004): 5I-62. 
—. "From Politics to Biopolitics ... and Back". The South Atlantic Quarterly 103. 2-3 (2004): 501-521.

—. “Jacques Lacan's Four Discourses”. Lacan.com. S.pag. Web. 